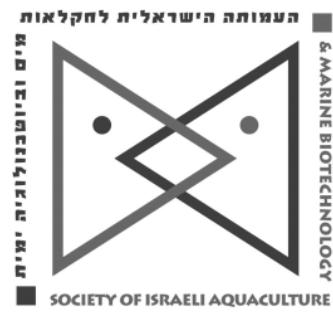

The IJA appears exclusively as a peer-reviewed on-line open-access journal at http://www.siamb.org.il. To read papers free of charge, please register online at registration form.

Sale of IJA papers is strictly forbidden.

\title{
Short-term Cycles of Feed Deprivation and Refeeding on Growth Performance, Feed Utilization, and Fillet Composition of Hybrid Tilapia (Oreochromis mossambicus $\mathbf{x}$ o. niloticus)
}

\section{Ndakalimwe Naftal Gabriel ${ }^{1 *}$, Edosa Omoregie ${ }^{1}$, Martin Tjipute ${ }^{1}$, Lesley Kukuri $^{2}$, Lahjia Shilombwelwa ${ }^{2}$ \\ ${ }^{1}$ Department of Fisheries and Aquatic Sciences, Sam Nujoma Campus, University of Namibia, Henties Bay, Namibia; \\ ${ }^{2}$ Directorate of Aquaculture, Ministry of Fisheries and Marine Resources, Hardap, Namibia}

Keywords: aquaculture; compensatory growth; feed management; tilapia

\begin{abstract}
This study was designed to determine the effect of short-term starvation and refeeding cycles on growth performance, feed utilization, and muscle composition of hybrid tilapia (Oreochromis mossambicus $\times$ O. niloticus). A total of 360 juveniles $(5.53 \pm 0.38 \mathrm{~g})$ were randomly divided into 12 tanks in triplicate groups. The control group (C) was fed three times a day to satiation. The feeding regimes of the other groups were designed as follows: 2 days deprivation / 2 days refeeding (2DD2DRF), 2 days deprivation /3 days refeeding (2DD3DRF), and 2 days deprivation / 4 days refeeding (2DD4DRF). Fish in 2DD4DRF group presented complete compensatory growth; no significant difference was observed in growth performance parameters compared to C. Hepatosomatic index, viscerosomatic index, and condition factor was not affected by these feeding regimes. Moreover, better feed conversion ratio, feed efficiency ratio, and protein efficiency ratio values were observed in feed deprived fish, with the best parameters observed in fish under 2DD4DRF feeding regime. Meanwhile, muscle crude protein and lipid content in 2DD2DRF and 2DD3DRF was significantly lower compared to $C$ and 2DD4DRF group.
\end{abstract}

* Corresponding author. E-mail: ngabriel@unam.na 
Gabriel et al.

\section{Introduction}

In tilapia farming, feed costs constitute about $60-70 \%$ of the total production costs (Borski et al., 2011). As feed prices keep rising in the world markets this has made it hard to convert the benefits of higher biological production associated with commercial feed into economic gains when fed fish are fed following traditional practices. In an effort to maximize aquaculture profits, fish farmers have adopted various feed management strategies, which reduce feed input (Cuvin-Aralar et al., 2012), reduce water quality problems as well as labor costs (Blanquet and Oliva-Teles, 2010). Some of these strategies include mixed feeding such as alternative commercial pellets with farm-made feed, and restricted feeding such as feeding by body weight, or feed deprivation and refeeding cycles, with fish normally fed to satiation during the refeeding period (Ali et al., 2003).

Feed restriction is a feed management strategy which has attracted wide interest in aquaculture (Yengkokpam et al., 2013; Ren et al., 2015). This strategy is believed to take advantage of a phenomenon called compensatory growth, which is described as an accelerated growth rate resulting from an appropriate refeeding of the fish after a period of feed restriction or exposure to unfavorable conditions such as low temperature, low oxygen, and reproductive effort (Ali et al., 2003). Compensatory growth can be classified as overcompensation, complete compensation, or partial compensation; it also depends on the species, the duration, and extent of the process (Hayward et al., 1997).

Despite extensive studies on compensatory growth in fish, equivocal results have been reported. For example, complete compensatory growth was reported in Lates calcarifer (Tian and Qin, 2003), over-compensatory growth in hybrid sunfish (Lepomis cyanellus x Lepomis macrochirus) (Hayward et al., 1997), and no compensatory growth was reported in Cyprinus carpio (Schwarz et al., 1985). Similarly, inconsistent results were documented in tilapia species such as complete compensation in Oreochromis niloticus (Passinato et al., 2015), partial compensation in hybrid tilapia (O. mossambicus x O. niloticus) (Wang et al., 2000), and a lack of compensatory growth in Oreochromis niloticus (Yang et al., 2015). Sufficient information is required to explain these inconsistent findings between and among fish species reared under different experimental systems and feeding protocols. Compensatory growth is of interest in aquaculture, and an understanding of its dynamics may allow the design of feeding regimes which improve production, save feed cost, labor cost, and reduce water quality problems (Wang et al., 2000). The aim of this study was to investigate the effect of short-term cycles of feed deprivation and refeeding on growth performance, feed utilization, and muscle composition of hybrid tilapia (O. mossambicus $\times$ O. niloticus). To the best of our knowledge, this is one of the few studies on compensatory growth in hybrid tilapia ( $O$. mossambicus $\times 0$. niloticus) testing shorter feed restriction/refeeding cycles which have been shown to be effective at inducing compensatory growth in fish.

\section{Materials and Methods}

Fish and management. The experiment was conducted at Hardap Inland Aquaculture Center in a closed recirculating water system in Namibia, May 2016. The experimental fish (tilapia hybrid, $O$. mossambicus $\times 0$. niloticus) with an average body weight of $5.53 \pm 0.38 \mathrm{~g}$ were stocked in cylindrical white polyethylene tanks. They were supplied with $340 \mathrm{~L}$ of freshwater at $29.04 \pm 0.45^{\circ} \mathrm{C}(\mathrm{pH} 8.1 \pm 0.47$, dissolved oxygen (DO) $5.79 \pm 0.37 / \mathrm{mgL}$ (HACH- HQ40d multiple parameter meter, Inc. USA) with adequate aeration and under natural photoperiod on a commercial diet (38\% crude protein, Aquanutro Pty, Ltd., Malmesburry, South Africa), which was administered three times a day (0900, 1300, and 1700), until apparent satiation. Two thirds of the water volume was replaced bi-weekly to maintain water quality, during acclimatization period.

Experimental design. Fish were randomly distributed into 12 tanks ( 3 treatments, 4 replications) at a stocking density of $30 \mathrm{fish} / \mathrm{tank}$, after acclimatization. Fish in group 1 (control) were fed daily until satiation, the other groups were fed as follows: 2 days starvation/2 days refeeding (2DD2DRF) (15 cycles), 2 days starvation/3 days refeeding 
(2DD3DRF) (12 cycles), 2 days starvation/4 days refeeding (2DD4DRF) (10 cycles) for 60 days. Refeeding was carried out three times a day (0900: 1300: 1700) until apparent satiation. This design is a modification of that used by Urbinati et al. (2014). During the experiment, growth conditions were maintained by continuous aeration, water recirculation, and replacement of $60 \%$ of the water in all tanks bi-weekly with freshwater of similar temperature to maintain the water quality during the study.

Water conditions were: temperature $28.8 \pm 0.36, \mathrm{pH}=7.8 \pm 0.36, \mathrm{DO} 6.1 \pm 0.31 / \mathrm{mgL}$, Ammonia-Nitrogen free and photoperiod $12 \mathrm{~h}$ light /dark cycle.

Fish growth, and feed utilization performance. Fish growth was evaluated in terms of final weight (FW), weight gain (WG), specific growth rate (SGR), hepatosomatic index (HSI), viscerosomatic index (VSI), and condition factor (CF). Feed utilization parameters included feed intake, (FI), feed conversion ratio (FCR), feed efficiency ratio (FER), and protein efficiency ratio (PER). Survival was expressed as percentages. Body weight and length of all the fish in each tank were measured $24 \mathrm{~h}$ after the last experimental feeding. Liver and gutted weights of three fish from each replicate were recorded, respectively. During the trial, the amount of feed consumed and mortality in each replicate was recorded.

Muscle proximate composition analysis. Dorsal muscles (fillets) from three fish in each replicate were collected and stored at $-20^{\circ} \mathrm{C}$ for proximate composition analysis (moisture, crude protein, crude lipid, and ash). Moisture content was determined by oven drying at $105^{\circ} \mathrm{C}$, until constant weight and expressed as percentage ( $\%$ moisture $=$ wet weight - dry weight /sample weight $\times 100$ ). Crude protein (nitrogen $\times 6.25$ ) was determined by the Kjeldahl method (Kjeltec ${ }^{\mathrm{TM}}$ 8200, Foss Analytic Co., Ltd., China) and was expressed as percentage. Crude lipid was determined by ether extraction system (Foss, Soxtec, 2043, Foss Scino, Co., Ltd) and was expressed as: \% lipid = (weight of residue /weight of the sample taken $\times 100$ ). Ash was determined by burning the dry samples at $560^{\circ} \mathrm{C}$ for $5 \mathrm{~h}$ and was as well also expressed as percentage.

Statistical analysis. Results for all parameters are expressed as mean \pm standard error $(M \pm$ $\mathrm{SE})$. Data were analysed using one-way analysis of variance (ANOVA) using statistical package for social sciences (SPSS Inc., USA). Tukey's test was used to determine differences between groups at $95 \%$ confidence level $(P=0.05)$.

\section{Results}

Growth performance and feed utilization parameters. Periodic feed deprivation and refeeding significantly $(P<0.05)$ influenced growth performance and feed utilization of hybrid tilapia $(O$. mossambicus $\times 0$. niloticus) (Table 1 ). FW, WG, and SGR was significantly lower $(P<0.05)$ in fish in the 2 days feed restriction/2 days refeeding cycle (2DD2DRF), and those in the 2 days starvation/3 days refeeding cycle (2DD3DRF) compared to those fed daily, and those in the 2 days feed restriction/4 days refeeding (2DD4DRF), respectively. Meanwhile, no significant differences $(P>0.05)$ in these parameters were observed in 2DD4DRF group when compared to the control. Feed deprivation and refeeding did not significantly affect $(P>0.05)$ HSI, VSI, and CF, however apart from CF, somewhat higher values were reported in the control group. FI was significantly lower $(P<0.05)$ in feed deprived fish when compared to the control, with 2DD2DRF and 2DD3DRF presenting the lowest amount among groups. No significant difference $(P>0.05)$ was recorded in FCR among groups, except lower values in feed deprived fish. Meanwhile, FER was significantly higher $(P<0.05)$ for fish in 2DD4DRF group compared to the control. PER was significantly lower $(P<0.05)$ in feed deprived fish compared to the daily fed fish, except those in 2DD4DRF group. Throughout the trial, no mortality was recorded. 
Gabriel et al.

Table 1. Growth performance and feed utilization parameters of hybrid tilapia (Oreochromis mossambicus $\times 0$. niloticus) reared at different feeding regimes.

\begin{tabular}{lcccc}
\hline \multicolumn{2}{c}{ Parameters } & Control & 2DD2DRF & \multicolumn{2}{c}{ 2DD3DRF } & 2DD4DRF \\
FW & & & & \\
WG & $44.61 \pm 2.13^{\mathrm{c}}$ & $31.97 \pm 1.79^{\mathrm{a}}$ & $35.06 \pm 0.95^{\mathrm{ab}}$ & $40.99 \pm 3.26^{\mathrm{bc}}$ \\
SGR & $36.05 \pm 1.53^{\mathrm{b}}$ & $22.75 \pm 1.09^{\mathrm{a}}$ & $26.52 \pm 1.07^{\mathrm{a}}$ & $33.05 \pm 3.18^{\mathrm{b}}$ \\
HSI & $2.51 \pm 0.49^{\mathrm{b}}$ & $1.90 \pm 0.14^{\mathrm{a}}$ & $2.14 \pm 0.10^{\mathrm{ab}}$ & $2.39 \pm 0.17^{\mathrm{b}}$ \\
VSI & $1.74 \pm 0.32^{\mathrm{a}}$ & $1.60 \pm 0.15^{\mathrm{a}}$ & $1.62 \pm 0.27^{\mathrm{a}}$ & $1.68 \pm 0.16^{\mathrm{a}}$ \\
CF & $4.98 \pm 0.32^{\mathrm{a}}$ & $4.10 \pm 0.55^{\mathrm{a}}$ & $4.78 \pm 0.71^{\mathrm{a}}$ & $4.86 \pm 0.74^{\mathrm{a}}$ \\
FI & $1.88 \pm 0.28^{\mathrm{a}}$ & $2.06 \pm 0.10^{\mathrm{a}}$ & $2.13 \pm 0.11^{\mathrm{a}}$ & $2.20 \pm 0.23^{\mathrm{a}}$ \\
FCR & $75.11 \pm 0.93^{\mathrm{c}}$ & $50.94 \pm 1.70^{\mathrm{a}}$ & $54.28 \pm 1.70^{\mathrm{a}}$ & $59.67 \pm 1.20^{\mathrm{b}}$ \\
FER & $1.69 \pm 0.07^{\mathrm{a}}$ & $1.58 \pm 0.12^{\mathrm{a}}$ & $1.52 \pm 0.07^{\mathrm{a}}$ & $1.39 \pm 0.12^{\mathrm{a}}$ \\
PER & $0.59 \pm 0.03^{\mathrm{a}}$ & $0.64 \pm 0.05^{\mathrm{ab}}$ & $0.66 \pm 0.03^{\mathrm{ab}}$ & $0.73 \pm 0.04^{\mathrm{b}}$ \\
Survival (\%) & $0.95 \pm 0.04^{\mathrm{c}}$ & $0.60 \pm 0.03^{\mathrm{a}}$ & $0.69 \pm 0.04^{\mathrm{ab}}$ & $0.87 \pm 0.08^{\mathrm{bc}}$ \\
& $100 \pm 0.00^{\mathrm{a}}$ & $100 \pm 0.00^{\mathrm{a}}$ & $100 \pm 0.00^{\mathrm{a}}$ & $100 \pm 0.00^{\mathrm{a}}$ \\
\hline
\end{tabular}

${ }^{a}$ Data are expressed as mean \pm standard error $(M \pm S E), n=3$. Values with different superscript letters in the same row are significantly different $(P<0.05)$. Where, FW = final weight, WG =weight gain, SGR = specific growth rate, HSI = hepatosomatic index, VSI = viscerosomatic index, $\mathrm{CF}=$ condition factor, $\mathrm{FI}=\mathrm{Feed}$ intake, FCR = food conversion ratio, FER = Feed efficiency ratio, and PER = Protein efficiency ratio.

Muscle proximate composition analysis. Consecutive feed deprivation and subsequent refeeding also had significant effect $(P<0.05)$ on some muscle composition parameters of hybrid tilapia (O. mossambicus $\times 0$. niloticus) (Table 2 ). Crude fat, and crude protein content was significantly lower $(P>0.05)$ in feed deprived fish compared to daily fed fish, with the lowest contents presented in 2DD2DRF and 2DD3DRF fish among groups. Meanwhile, no significant difference $(P>0.05)$ was observed in the moisture and ash content of feed deprived fish when compared to the daily fed ones.

Table 2. Fillet composition of hybrid tilapia (Oreochromis mossambicus $\times$ O. niloticus) subjected to different feeding regimens.

\begin{tabular}{lccll}
\hline Parameters (\%) & Control & 2DD2DRF & 2DD3DRF & 2DD4DRF \\
\hline Moisture & $66.38 \pm 0.79^{\mathrm{a}}$ & $70.75 \pm 0.81^{\mathrm{a}}$ & $69.87 \pm 1.32^{\mathrm{a}}$ & $68.89 \pm 0.69^{\mathrm{a}}$ \\
Crude fat & $11.44 \pm 0.01^{\mathrm{a}}$ & $7.43 \pm 0.08^{\mathrm{b}}$ & $7.98 \pm 0.56^{\mathrm{b}}$ & $9.84 \pm 0.33^{\mathrm{c}}$ \\
Crude protein & $80.03 \pm 0.01^{\mathrm{a}}$ & $76.09 \pm 0.67^{\mathrm{b}}$ & $76.89 \pm 0.89^{\mathrm{b}}$ & $78.94 \pm 0.20^{\mathrm{ab}}$ \\
Ash & $6.40 \pm 0.56^{\mathrm{a}}$ & $5.54 \pm 0.25^{\mathrm{a}}$ & $5.80 \pm 0.51^{\mathrm{a}}$ & $6.43 \pm 0.21^{\mathrm{a}}$ \\
\hline
\end{tabular}

${ }^{\mathrm{a}}$ Data are expressed as mean \pm S.E., $\mathrm{n}=3$. Different superscripts in the same row indicate significant differences $(P$ $<0.05$ ).

\section{Discussion}

The results of the present study demonstrate compensatory growth in hybrid tilapia ( $O$. mossambicus $\times 0$. niloticus) during feed deprivation/refeeding cycles. Fish subjected to 2 days deprivation/4 days refeeding cycle showed complete compensatory growth in terms of body mass, as those fed continuously (Jobing et al.)

In agreement with our study, Abdel-Hakim et al. (2009) reported complete compensatory growth in hybrid tilapia ( $O$. niloticus $\times 0$. aureus) starved once and twice a week, respectively. They further indicated that a moderate feed deprivation regime $(1$, or 2 days per week) showed a significant reduction in feeding costs without growth depression compared to continuous feeding. Moreover, full compensatory growth was reported in Nile tilapia (Passinato et al., 2015; Cuvin-Aralar et al., 2012); Lates calcarifer (Tian and Qin, 2003) subjected to different feed restriction /refeeding regimes, respectively.

Several studies have shown that fish subjected to severe or lengthy feed deprivation cycles have shown poor compensatory growth. For instance, in the current study poor growth performance was observed in fish subjected to 2 days feed deprivation/2 days 
refeeding, and 2 days feed deprivation/3 days refeeding cycles when compared to those fed daily and those fed 4 days per week, respectively. Correspondingly, hybrid tilapia juveniles ( $O$. niloticus $\times 0$. aureus) deprived of feed 3 days per week showed poor growth compared to those deprived for 1 and 2 days, respectively (Abdel-Hakim et al., 2009). Poor compensatory growth in fish exposed to longer deprivation periods were also reported in Nile tilapia (Passinato et al., 2015), O. mossambicus (Christensesn and Mclean, 1998), and other species such as Centropomus parallelus (Ribeiro and Tsuzuki, 2010) and Sparus aurata (Peres et al., 2011).

To date, although there have been numerous studies, mechanisms for compensatory growth are poorly understood in fish. However, various studies have suggested that compensatory growth in fish could be a result of low basal metabolism (Fu et al., 2005), increased feed intake (hyperphagia) (Xie et al., 2001), or improved feed utilization indices such as FCR and FER (Adakli and Tasbozan, 2015) following period of starvation or intermittent feeding. Improved feed utilization parameters have been observed in many fish including hybrid tilapia (O. niloticus x O. aureus) (Abdel-Hakim et al., 2009), Nile tilapia (Passinato et al., 2015), and even in shellfish such as Fenneropenaeus chinesis (Zhang et al., 2010) exposed to feed deprivation and refeeding regimes. Improvement in these parameters has been attributed to increased digestive capacity during refeeding period (Bolasina et al., 2006). For instance, enhanced digestive activities were reported in Labeo rohita (Yengkokpam et al., 2013), and Atlantic salmon (Krogdahl and Bakke-Mckellep, 2005) subjected to feed deprivation and refeeding regimes. Higher protease activities in $F$. chinesis juveniles during refeeding has been reported, and improved FER and feed intake parameters and better growth performance compared to the control group (Zhang et al., 2010). The present study reported lower FCR and higher FER in fish submitted to feed deprivation /refeeding regime compared to those fed daily, with fish submitted to a 2 days deprivation /4 days refeeding cycle representing the lowest FCR and the highest FER values. This could be a result of improved feed utilization and digestive enzymes activities during the refeeding period as demonstrated in earlier studies. This is also an indication that short-term feed deprivation/refeeding cycles could indeed be a useful tool in reducing feed amount without compromising fish farm production output.

Similar to growth performance and feed utilization parameters, mixed results were obtained for body composition in fish subjected to feed restriction/refeeding regimes. Studies on channel catfish (Ictalurus punctatus) (Gaylord and Garlin, 2000), gilbel carp (Xie et al., 2001), hybrid stripped bass, Moronechrysops x Morone saxatilis (Turano et al., 2007) failed to report significant effect of feeding management strategies on body composition. However, a significant reduction of total lipid in Decentrarchus labrax starved for 10 days and re-fed 40 days when compared to the control (fed daily) was reported (Adakli and Tasbozan, 2015). Comparably, lower body lipid content in fish subjected to starvation /refeeding regimes were reported in various studies (Tian and Qin, 2003; Peres et al., 2011). These findings partly concur with the present study, which showed significantly lower muscle lipid and protein in 2DD2DRF and 2DD3DRF fish compared to the control. These fish were unable to restore lipid and protein content utilized during starvation period to support basal metabolism and survival as explained by Adakli and Tasbozan (2015). This is an indication that severe or long term feed deprivation/refeeding cycles can result in less fattening and higher energy consumption in fish as a result of glycolytic activities during starvation.

In conclusion, short-term feed deprivation and refeeding cycles had an influence on growth performance, feed utilization, and muscle composition parameters of hybrid tilapia ( $O$. mossambicus $\times 0$. niloticus), and 2 days deprivation $/ 4$ days refeeding cycle 
Gabriel et al.

appears to be optimal. However, further studies on economical aspects, water quality parameters, and physiological responses of fish following feed deprivation and refeeding regimes are deemed necessary.

\section{Acknowledgements}

The authors are grateful for the financial assistance and facilities provided by the Ministry of Fisheries and Marine Resources (MFMR), directorate of aquaculture, Namibia. All authors give their sincere thanks to Mr Iyambo Andreas, and Ms. Elizabeth Ndivayele (Onavivi feed manufacturing station) for their technical assistance and provision of facilities for muscle and feed proximate analysis.

\section{References}

Abdel-Hakim N.F., Abo State H.A., Al-Azab A.A. and F.K. El-Kholy, 2009. Effect of feeding regimes on growth performance of juvenile hybrid Tilapia (Oreochromis niloticus $\mathrm{x}$ Oreochromis aureus). World J. Agric., Sci., 5: 49-54.

Adakli A. and 0. Tasbozan, 2015. The effects of different cycles of starvation and refeeding on growth and body composition on European seabass (Dicentrarchus labrax). Turk. J. Fish. Aquat. Sc., 15: 419-427.

Ali M., Nicieza A. and R.J Wooton, 2003. Compensatory growth in fishes: a response to growth depression. Fish Fish., 4:147-190.

Blanquet I. and A. Oliva-Teles, 2010. Effect of feed restriction on the growth performance of turbot (Scophthalmus maximus L.) juveniles under commercial rearing conditions. Aquac. Res,. 41:1255-1260.

Bolasina S., Perez A. and Y. Yamashita, 2006. Digestive enzymes activity during ontogenetic development and effect of starvation in Japanese flounder, Paralichthys olivaceus. Aquaculture, 252: 503-515.

Borski R.J., Bolivar R.B., Jimenez E.B.T., Sayco R.M.V., Arueza R.L.B., Stark C.R. and P.R. Ferket, 2011. Fishmeal-free diets improve the cost effectiveness of culturing Nile tilapia (Oreochromis niloticus, L.) in ponds under an alternate day feeding strategy. In: L. Liping, K. Fitzsimmons (eds). Proceedings of the Ninth International Symposium on Tilapia in Aquaculture. Shanghai, China. p. 95-101.

Christensesn S. M. and E Mclean, 1998. Compensatory growth in Mozambique tilapia (Oreochromis mossambicus), fed a suboptimal diet. Croat. J. Fish., 56: 3-19.

Cuvin-Aralar L.M., Gibbs P., Palma A., Andayog A. and L. Noblefranca, 2012. Skip feeding as an alternative strategy in the production of Nile tilapia Oreochromis niloticus (Linn.) in cages in selected lakes in the Philippines. Philipp. Agric. Sci., 95: 378-385.

Fu S.J., Xie X.J. and Z.D. Cao, 2005. Effect of fasting on resting metabolic rate and postprandial metabolic response in Silurus meridionalis. J Fish Biol., 67: 279-285.

Gaylord T.G. and D.M. Gatlin III, 2000. Assessment of compensatory growth in Channel catfish, Ictalurus punctatus, R. and associated changes in body condition indices. J. World Aquac. Soc., 31: 326-336.

Hayward R.S., Noltie D.B. and N. Wang, 1997. Use of compensatory growth to double hybrid sunfish growth rates. Trans. Am. Fish. Soc., 126, 316-322.

Jobing M., Koskela J. and S. Winberg, 1999. Feeding and growth of whitefish fed restricted and abundant rations: influences on growth heterogeneity and brain serotonergitic activity. J. Fish Biol., 54: 437-449.

Krogdahl A. and A.M. Bakke-Mckellep, 2005. Fasting and refeeding cause rapid changes in intestinal tissue mass and digestive enzyme capacities of Atlantic salmon (Salmo salar L.). Comp. Biochem. Physiol A. 141:450-460.

Passinato B.E., de Magalhaes Junior F.O., Cipriano S.F., de Souza B.H.R., de Lima S.K., Chiapetti J. and T.G.L Braga, 2015. Performance and economic analysis of the production of Nile tilapia submitted to different feeding regime. Supplemento, 36:4481- 4492. 
Peres H., Santos S. and A. Oliva-Teles, 2011. Lack of compensatory growth response in gilthead sea bream (Sparus aurata) juveniles following starvation and subsequent refeeding. Aquaculture, 318: 384-388.

Ren M., Habte-Tsion H-M., Liu B., Xie J., Ge X.*, Zhou Q., Pan L., 2015. Food deprivation of blunt snout bream, Megalobrama amblycephala fingerlings and the subsequent effect of refeeding with different dietary starch levels on glucose metabolism, 9 pages. Isr. J. Aquacult.-Bamidgeh, 67.2015.1188,

Ribeiro F.F. and M.Y. Tsuzuki, 2010. Compensatory growth responses in juvenile fat snook, Centropomus parallelus Poey, following food deprivation. Aquacult. Res., 41: 226-233.

Schwarz F.J., Plank J. and M. Kirchgessner, 1985. Effects of protein or energy restriction with subsequent reali-mentation on performance parameters of carp (Cyprinus carpio L.). Aquaculture, 48: 23-33.

Tian X. and J.G Qin, 2004. Effects of previous ration restriction on compensatory growth in barramundi Lates calcarifer. Aquaculture, 235: 273-283.

Turano M.J., Borski R.J. and H.V. Daniels, 2007.Compensatory growth of pond-reared hybrid striped bass, Moronechrysops x Morone saxatilis, fingerlings. J World Aquac Soc, 38: 250-261.

Urbinati C.E., Sarmiento S.J. and S.L. Takahashi, 2014. Short-term cycles of feed deprivation and refeeding promote full compensatory growth in the Amazon fish matrinxa (Brycon amazonicus). Aquaculture, 433: 430-433.

Wang Y., Cui Y., Yang Y. and F. Cai, 2000. Compensatory growth in hybrid tilapia, Oreochromis mossambicus $\times 0$. niloticus, reared in seawater. Aquaculture, 189: 101-108.

Xie S., Zhu X., Cui Y., Wooton R.J., Lei W. and Y. Yang, 2001. Compensatory growth in the gibel carp following feed deprivation: Temporal patterns in growth, nutrient deposition, feed intake and body Composition. J. Fish Biol., 58: 99-1009.

Yang G., Ziwei W., Jun-wook H. and L. Jeong-Yeol, 2015. Body composition and compensatory growth in Nile tilapia Orechromis niloticus under different feeding intervals. Chin. J. Oceanol. Limn., 33: 945-956.

Yengkokpam S., Debnath D., Pal A.K., Sahu N.P., Jain K.K., Norouzitallab P. and K. Baruah, 2013. Short-term periodic feed deprivation in Labeo rohita fingerlings: effect on the activities of digestive, metabolic and anti-oxidative enzymes. Aquaculture, 412-413: 186-192.

Zhang P., Zhang X., Li T. and T. Gao, 2010. Effects of refeeding on the growth, and digestive enzyme activities of Fenneropeneaus chinesis juveniles exposed to different periods of food deprivation. Aquacult Int., 18: 1191-1203. 